\title{
Our surgical experiences on vascular injuries in Afrin Olive Branch operation
}

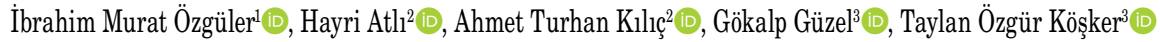 \\ ${ }^{1}$ Department of Cardiovascular Surgery, Firat University Faculty of Medicine, Elazlğ, Turkey \\ ${ }^{2}$ Department of Cardiovascular Surgery, Bursa State Hospital, Bursa, Turkey \\ ${ }^{3}$ Department of Cardiovascular Surgery, Gaziantep Dr. Ersin Arslan Training and Research Hospital, Gaziantep, Turkey
}

\begin{abstract}
Objectives: In this study, we present our surgical experiences on vascular injuries during the Afrin Olive Branch operation of Turkey. Patients and methods: Between February 2018 and May 2018, a total of 37 traumatized patients (36 males, 1 females; mean age 26.8 years; range, 17 to 55 years) with vascular injuries who were treated by cardiovascular surgeons during the Afrin Olive Branch operation were included in this study.

Results: A total of 37 patients underwent 46 vascular surgical procedures. There were no surgery-related mortalities during follow-up. Twenty patients (54\%) were discharged and 17 patients (46\%) were transferred to an external center in the postoperative early period.

Conclusion: Based on our experiences, we suggest that major arterial injuries should be repaired rather than direct amputation, and the saphenous vein must be used for bypass or interposition, where applicable.
\end{abstract}

Keywords: Surgery, vascular injury, war.

Massive blood loss due to limb injuries is the most common cause of preventable deaths in wars. For these situations, first aid and timely manner are vital before hospital admission. Therefore, it is essential that the teams, who are responsible for the first aid, must be located at a safe point closest to the battlefield, as well as experienced medical personnel. The closest center to the battlefield where the first intervention is to be carried out, as well as the life-saving and disability preventive intervention is of utmost importance.

In case of war setting, there are many lifethreatening injuries in a body which requires the involvement of many surgical departments at the same time. ${ }^{[1]}$ The follow-up and additional interventions of these procedures in the intensive care unit for the first 24 to 48 hours are almost routinely seen. Due to the natural history of the war, the center where these first surgical interventions are performed should be circulated due to the high likelihood of a number of wounded patients. Therefore, patients should be transported to other well-equipped centers as far as possible, when appropriate transfer conditions are achieved. In this way, it would be possible to both relieve the center personnel loaded with densities and refresh the necessary minimum conditions in the hospital. ${ }^{[2]}$ Although major vascular procedures have become widespread in surgical applications, when faced with multiple patient influx, vascular repair may sometimes cause unnecessary time loss. In such cases, accepting a simple ligation and amputation may be the most appropriate clinical decision.

Vascular injuries are often due to the association of a trauma in the other body regions. Although 50 to $75 \%$ of war injuries involve limb injuries, only 1 to $2 \%$ suffer from major vascular injuries. However, this ratio may increase up to $\geq 5 \%$ where modern body armor and anti-personnel mines are widely used, offering more protection to the head. A surgical team who worked on the Cambodian-Thai border in 1988 witnessed the spread of landmines, intervened 94 war-wounded in

Received: February 08, 2019 Accepted: April 01, 2019 Published online: July 25, 2019

Correspondence: İbrahim Murat Özgüler, MD. Firat Üniversitesi Tıp Fakültesi Kalp ve Damar Cerrahisi Anabilim Dalı, 23090 Elazı̆̆, Turkey. e-mail: drmuratozg@hotmail.com 
a battle and found that $13.8 \%$ of them had vascular injuries in the lower limbs. ${ }^{[3]}$ In many historical series, major arterial injuries of the lower limbs are almost twice as high as upper limb artery injuries. ${ }^{[3]}$ However, the brachial artery is the most or the second most common major peripheral injured artery. ${ }^{[3]}$ The probable cause is that the brachial artery has a very superficial anatomy and the normal activity of the soldier in the war exposes this artery more relative to trauma. ${ }^{[4-7]}$ In the literature, the relative incidence of isolated major venous injuries is unclear, and lower limb venous injuries are more common.

In the present study, we report our surgical experiences on vascular injuries during the Afrin Olive Branch operation of Turkey. The aim of this study is to show the capabilities of our country in the field of war surgery and to shed light on the surgical teams which are capable of performing emergency interventions for our military and civilian citizens in other probable future operations.

\section{PATIENTS AND METHODS}

Between February 2018 and May 2018, a total of 37 traumatized patients (36 males, 1 females; mean age 26.8 years; range, 17 to 55 years) with vascular injuries who were treated by cardiovascular surgeons at the Kirıkhan State Hospital in Hatay province as the first aid center assigned by the Republic of Turkey, Ministry of Health during the Afrin Olive Branch operation were included in this study. The patients with injuries were transferred from Syria's Afrin district. All data were evaluated by examining the digital emergency patient records and operation reports of our surgical teams. Data including age, sex, arrival time, injury type, accompanying injuries, cardiovascular interventions, morbidity, anatomic localization of the vascular injury, hospitalization, radiological examination, abnormal biochemistry findings, and the outcomes were evaluated.

Initially, the patients were transferred from the battle site by the National Medical Rescue Team (UMKE). After delivering the first interventions, a short message service was send to the team at Kirıkhan State Hospital, when the patient was deployed in the border region for sharing emergency information. According to the number of injured patients, at least one specialist from each surgical department met the patient with a multidisciplinary approach in the emergency unit. Approximately 10 to $15 \mathrm{~min}$ after the arrival of the emergency room, all necessary radiological and biochemical tests and blood group test results were obtained. According to the decision of the surgical team, whether the patient had a poor general condition and hemodynamic instability or not was decided. Therefore, six of the injured patients underwent intraoperative exploration of the injury sites without any examination and emergency surgery was performed by the relevant department. All of the patients who were considered to have a vascular pathology were examined with a hand Doppler in the emergency department by a cardiovascular surgeon and advanced imaging studies were performed, if necessary, to confirm the diagnosis.

\section{Statistical analysis}

Statistical analysis was performed using the SPSS version 20.0 software (IBM Corp., Armonk, NY, USA). Descriptive data were expressed in mean and standard deviation (SD) and number and frequency.

\section{RESULTS}

The majority of the patients (83\%) were in the 20 to 30 age range. Of the patients, 17 (45\%) had gunshot wounds, 11 (29\%) had handmade explosive wounds, four (10\%) had mine burst wounds, two (5\%) had a crush injury, and two (5\%) had penetrating injuries (Table 1).

Thirty-three of the patients (89\%) were transferred to the hospital by ambulance and four (11\%) by helicopter. The mean time to hospitalization was $28.4 \mathrm{~min}$ (range, 20 to $45 \mathrm{~min}$ ). These data were calculated using time to receive of short messages for each patient.

\begin{tabular}{lcc} 
Table 1. Causes of injuries & & \\
\hline & $\mathrm{n}$ & $\%$ \\
\hline Gunshot wound & 17 & 45 \\
Handmade explosives & 11 & 29 \\
Mine & 4 & 10 \\
Crush injury & 2 & 5 \\
Penetrating injury & 2 & 5 \\
\hline
\end{tabular}

\section{Table 2. Imaging techniques}

\begin{tabular}{lcc}
\hline & $\mathrm{n}$ & $\%$ \\
\hline Computed tomography angiography & 5 & 13 \\
Roentgenogram & 11 & 29 \\
Computed tomography & 7 & 18 \\
Computed tomography + roentgenogram & 6 & 16 \\
Arterial Doppler ultrasonography & 1 & 2 \\
Echocardiography & 1 & 2
\end{tabular}


Computed tomography angiography (CTA) was performed in five patients with a suspicious vascular lesion with no distal pulse and without major hemorrhage. Computed tomography (CT) was performed in 18, direct radiographs in six, Doppler ultrasonography (USG) in one, and preoperative echocardiography (ECHO) in one patient (Table 2).

On cardiovascular examination, the femoral artery was injured in 11 (28\%), popliteal artery in eight (20\%), infrainguinal popliteal artery in six (16\%), brachial artery in four (10\%), carotid artery in three (7\%), sternal-intercostal arteries in two (5\%), axillarysubclavian arteries in two (5\%), distal brachial artery in two (5\%), and abdominal aorta in one (2\%) patient (Table 3). Multiple limb injuries were simultaneously associated with multiple effects of the shrapnels in some patients.

After the multidisciplinary evaluation, 19 of 37 patients had injuries which were not related to cardiovascular surgery. Patients who were diagnosed for vascular injury had at least one limb area injuries, except for the vascular injury site in $51 \%$. In the examination of the injuries of these 19 patients, eight (22\%) had total limb amputation, six (17\%) had thoracic injuries, five (14\%) had abdominal injuries, four (11\%) had tibial fractures, three (8\%) had femoral fractures, two (5\%) had eye injuries, three (5\%) had foot amputations, two (5\%) had arm fractures, one (3\%) had body burns, one (3\%) had head injury, and one $(3 \%)$ had neck injury in addition to vascular injuries.

In all patients, UMKE teams administrated the respiratory support and vascular access lines. When the injured patients were admitted to the emergency room, routine complete blood count and biochemical parameters with blood group tests were studied and taken to the operation room to evaluate intraoperatively then the operation was started urgently. The hematocrit

\begin{tabular}{lcc} 
Table 3. Vascular injuries & & \\
\hline & $\mathrm{n}$ & $\%$ \\
\hline Femoral artery & 11 & 28 \\
Popliteal artery & 8 & 20 \\
Distal popliteal artery & 6 & 16 \\
Brachial artery & 4 & 10 \\
Carotid artery & 3 & 7 \\
Sternal intercostal artery & 2 & 5 \\
Axillary-subclavian artery & 2 & 5 \\
Distal brachial artery & 2 & 5 \\
Abdominal aorta & 1 & 2 \\
\hline
\end{tabular}

values were observed to be low due to the massive blood loss in the patients (mean: 22.6\%). Only 24 (64\%) of 37 patients had no other procedure and the blood tests could be requested at the first time. The white blood cell counts of three patients $(12 \%)$ were found to be over $20,000 \mu \mathrm{L}$, while the platelet levels of three patients $(12 \%)$ were below $40,000 \mathrm{~mm}^{3}$. The hematocrit values were found to be in the 14 to 16 range in all of these three patients with low platelet levels.

Thirty-seven injured patients had a cardiovascular pathology, and 46 surgical procedures applied within the first 30 min following the arrival to the hospital. Ischemia follow-up was initiated with anticoagulant treatment, if the absence of any contraindication due to ischemia in 10 patients in the lower limb and one patient in the upper limb. None of these patients suffered from any loss of limb and no ischemia was detected during the hospitalization. One of the patients had pericardial fluid and underwent ECHO follow-up due to blunt chest trauma. Anti-inflammatory and colchicine treatment was started and there was no increase in the pericardial fluid.

In total, 37 patients underwent 46 surgical procedures (Figures 1 and 2), (Table 4).

Patients who underwent surgery were transferred to the major centers, which were more equipped for

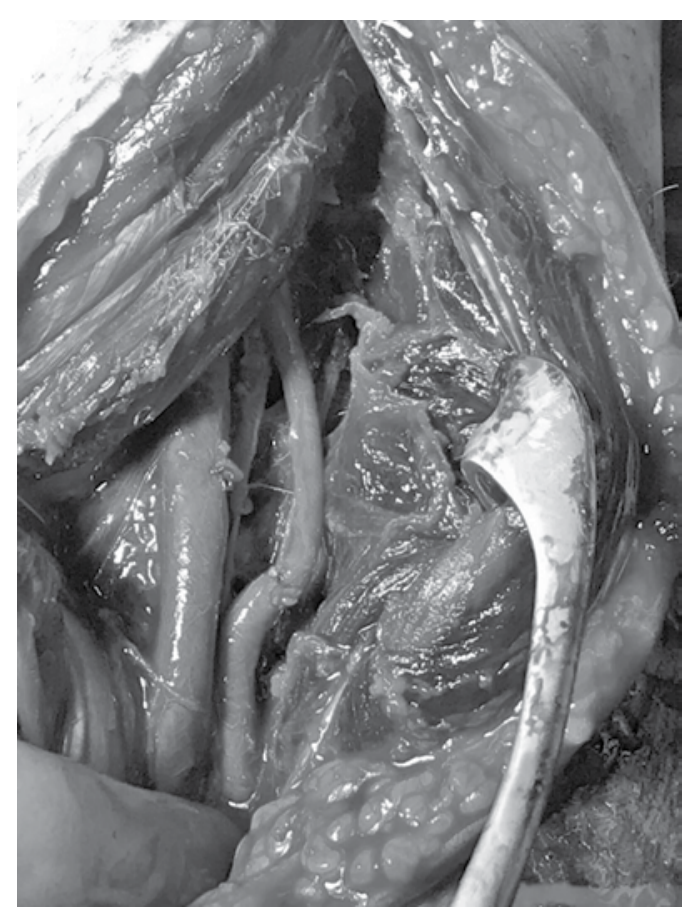

Figure 1. Saphenous vein interposition to brachial artery and vein. 


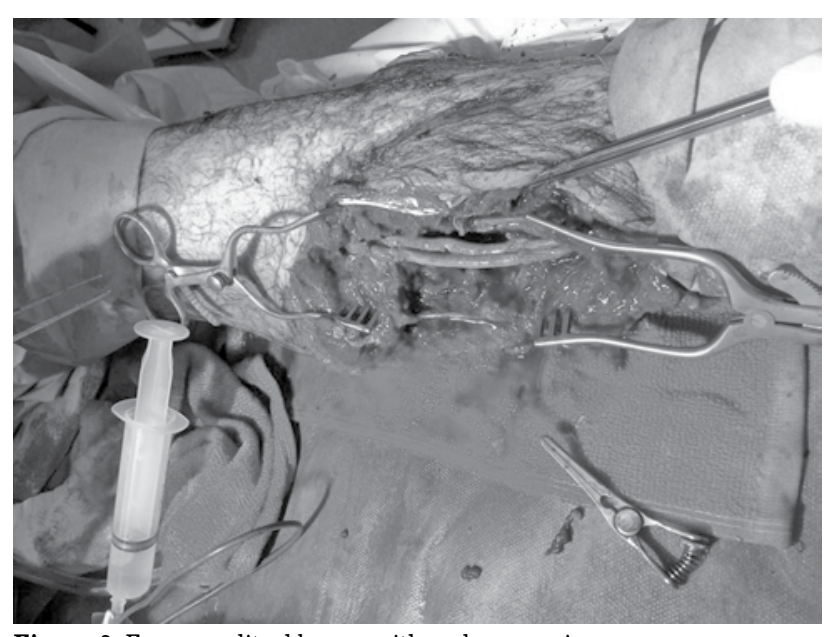

Figure 2. Femoropopliteal bypass with saphenous vein.

intensive care conditions after stabilization of the general condition as an application rule of the Hatay Province of Health Directorate. Postoperative early mortality and morbidity were evaluated. Of 37 injured patients, 20 (54\%) were discharged, 10 (21\%) were

\begin{tabular}{|c|c|c|}
\hline & $\mathrm{n}$ & $\%$ \\
\hline Femoro-popliteal infrainguinal bypass with saphenous vein & 3 & 6 \\
\hline Primary repair of femoral artery & 2 & 4 \\
\hline Primary repair of femoral vein & 1 & 2 \\
\hline Interposition of axillary artery with ePTFE graft & 1 & 2 \\
\hline Primary repair of axillary vein & 1 & 2 \\
\hline Primary repair of brachial artery & 1 & 2 \\
\hline Interposition of the brachial artery and vein with saphenous vein & 2 & 4 \\
\hline Primary repair of popliteal artery & 2 & 4 \\
\hline Primary repair of axillary artery & 1 & 2 \\
\hline Primary repair of abdominal aorta & 1 & 2 \\
\hline Femoro-popliteal supragenual bypass with saphenous vein & 1 & 2 \\
\hline Interposition of femoral vein with saphenous vein & 1 & 2 \\
\hline End to end anastomosis of posterior tibial artery & 1 & 2 \\
\hline End to end anastomosis of ulnar artery & 2 & 4 \\
\hline Small artery and vein ligation & 14 & 30 \\
\hline Brachial & 1 & \\
\hline Popliteal & 5 & \\
\hline Neck & 4 & \\
\hline Intercostal & 2 & \\
\hline Femoral & 2 & \\
\hline Vascular exploration & 8 & 17 \\
\hline Brachial & 1 & \\
\hline Carotid & 3 & \\
\hline Popliteal & 3 & \\
\hline Tibioperoneal & 1 & \\
\hline Lower extremity embolectomy & 2 & 4 \\
\hline Removal of foreign body from femoral artery & 1 & 2 \\
\hline
\end{tabular}

\begin{tabular}{lcc} 
Table 5. 0ther causes of morbidity & & \\
\hline & $\mathrm{n}$ & $\%$ \\
\hline Amputation of lower extremity & 10 & 27 \\
Lung injury & 6 & 16 \\
Amputation of foot & 5 & 13 \\
Abdominal injury & 5 & 13 \\
Tibia fracture & 4 & 11 \\
Eye perforation & 2 & 5 \\
Humerus fracture & 2 & 5 \\
Head injury & 1 & 2 \\
Neck injury & 1 & 2 \\
\hline
\end{tabular}

transferred to an external center in the postoperative first day, five $(10 \%)$ in the postoperative second day, and two (10\%) in the postoperative third day. There were no surgery-related mortalities and morbidities during follow-up. Other causes of morbidity included lower limb amputation in $10(27 \%)$, lobectomy in six (16\%), foot amputation in five (13\%), abdominal injury in five (13\%), tibial fractures in four (11\%), eye perforation in two (5\%), humeral fractures in two (5\%), head trauma in one (2\%), and neck injury in one $(2 \%)$ patient (Table 5).

\section{DISCUSSION}

It is well-known that the location of the injured area and the characteristics of the injured tissue are critical for the survey of the injury. ${ }^{[8]}$ As the density of the tissue increases, the amount of absorbed energy increases proportionally. Thus, it the total amount of the damage increases in the presence of multiple organ injury. ${ }^{[9-11]}$ In the present study, we observed that the morbidity and mortality rates of the patients were related with the other organs and tissues.

The most common vascular injuries which can be encountered in war surgery include transection or avulsion, laterally incisions or punctate wounds, contusions with or without intimal damage and thrombosis, isolated vasospasm, and pseudoaneurysm and arteriovenous fistula.

We believe that a cardiovascular surgery team has always benefits from the exploration of the region, if the patient has no suspicion of major vascular injury and there is no enough time for imaging studies. In our study, eight patients (17\%) underwent vascular exploration without surgical repair. If the location of the injury is consistent with the vascular tracing and the distal pulses cannot be palpated or poorly palpated with a hand Doppler, we believe that there is no drawback for the exploration of the region. 
In two of our patients, lower limb arterial exploration was performed and they had a complete vascular integrity; however, an arterial thrombus caused by intimal damage or shrapnel fragment was detected and the limb was rescued by embolectomy. In these two patients, arterial blood flow was detected poorly by a hand Doppler and could be easily thought to the other tissue injuries or due to the hemorrhagic shock. The appropriate location of the injury to the vascular anatomy should be evaluated with the intact limb and pulse comparison must be done in these patients.

In patients with long segmental vascular injuries, the saphenous vein should be the first choice for the interposition or bypass procedure. In our study, all but one of the peripheral bypasses and interpositions were applied with saphenous vein grafts. In a patient in whom an expanded polytetrafluoroethylene (ePTFE) graft was used for bypass, there was an axillary vein injury and widespread tissue loss in bilateral lower limb. Therefore, the artificial graft was used for the right diameter and without any loss of time by exploring for a vein graft. In a study comparing the saphenous vein and $\mathrm{PTTFE}$ grafts in peripheral bypasses in the lower limb, the limb salvage rate was $90 \%$ in the saphenous vein group and $62.9 \%$ in the ePTFE group. ${ }^{[12]}$ This ratio was $69.4 \%$ in the saphenous vein group and $55 \%$ in the ePTFE group for male patients.

There are reports of lower limb vascular injury in the war surgery and the cases are nearly twice as high as for the upper limb. A study also confirmed that these results were corresponded to 11 upper limb injuries and to 25 lower limb vascular injuries. It is evident that the lower limbs would be more affected during the war, mostly caused by the mines and handmade explosives. The closeness of the lower limbs to the explosive material and a higher area than the upper limb in the body might have also contributed to these ratios. ${ }^{[13]}$

In particular, in case of a vascular injury, a tourniquet application to the single bone-containing area and effective buffering on the open wound areas reduced mortality significantly. An effective and rapid airway support and intravenous volume replacement to the circulatory support also contributed to this success.

The presence of a large amount of limb defect and long segmental arterial damage may be seen in war injuries. Although arterial integrity is achieved, limb amputation may occur due to the absence of the tissue healing in the subsequent process of handmade explosives and mine injuries where extensive tissue and nerve damage are present. In such cases, it should be kept in mind that, if the patient is hemodynamically unstable, direct amputation can be a life-saving method without time loss for the revascularization. However, this decision must be made in collaboration with the orthopedics and surgery team. We believe that all organ injuries, not only vascular pathologies, should be treated simultaneously.

Another condition of being successful in the war surgery is not only in the manner of consultations in the emergency room, but also the multidisciplinary interventions are performed by general surgery, thoracic surgery, anesthesia, orthopedics, cardiovascular surgery, and neurosurgery at the same time. ${ }^{[14-16]}$ In this way, we determined the fast speed of implementation of the decisions and the time in gold for the injured was not wasted. Many patients with poor clinical condition and with no vital signs can be saved by taking out the operation areas without wasting any time. In this study, we observed that six injured patients were rescued in the emergency operating room and six of them recovered successfully. There must be at least five units of erythrocyte suspensions for each blood groups within the hospital to be used in the emergency setting. The Republic of Turkey, Ministry of Health and the Turkish Red Crescent provided the all blood reserves for each event in 30 min to Kirıkhan State Hospital. We believe that the ability to supply blood products for all blood groups also contributed to our success.

In available centers, angiography can be used for the patients with inadequate ischemia symptoms or for hemodynamically stable patients to detect an arteriovenous fistula or pseudoaneurysm more accurately. ${ }^{[17]}$ From the perspective of surgeons, it is the most optimal to deliver a $20 \mathrm{~mL}$ contrast agent in the operating room to perform a single injection of the proximal side of the vessel. If an appropriate $\mathrm{X}$-ray equipment (mobile $\mathrm{X}$-ray or $\mathrm{C}$-armed scopy) is not available in the operating room, the surgeon should go to the radiology department with the patient and apply that with no delay. The common femoral artery can be percutaneously cannulated with a thin 18 -gauge needle and the contrast agent can be rapidly injected. An X-ray is performed for two seconds later for the mid-thigh, three seconds for the distal thigh, and five seconds for the calf. In case of lower limb injury, the patient is given an opaque material from the femoral artery and a $\mathrm{C}$-arm scopy device shows the vascular injury intraoperatively. If there is an ultrasound Doppler probe, it may be useful, in addition to a careful clinical examination, particularly in uncertain 
vascular injuries. It not only provides the detection of the peripheral blood flow, but also calculation of the ankle-arm index (ABI). The cuff of a manual sphygmomanometer is wrapped around the ankle and a Doppler probe is placed over both the dorsalis pedis and posterior tibial arteries and the highest closing pressure is measured. This value is divided by the highest brachial systolic blood pressure to achieve ABI. A lower than 0.9 index suggests an arterial injury for the young patients. In the absence of the Doppler probe, a simple stethoscope can be used to retrieve the pulse of the posterior tibial artery. All patients with vascular injuries in our study were examined by cardiovascular surgeons in the emergency room with a hand Doppler. Five patients (13\%) without any major hemorrhage underwent CTA to identify the location of the vascular injury for a proper surgical strategy.

Furthermore, large arteries should be repaired as much as possible. Basic principles include bleeding control, exploration and control of the proximal and distal part of the vessels, preparation of the grafts, vascular repair and reconstruction, closure of the upper side of the artery with appropriate fascia or tissue, debridement and stabilization of the fractured bone, and fasciotomy. ${ }^{[18]}$ Fifteen of the injured patients underwent revascularization or repair of the major arteries, and no morbidity was observed as long as the patients were followed in the hospital. The saphenous vein grafts were used in all, but one patient. An

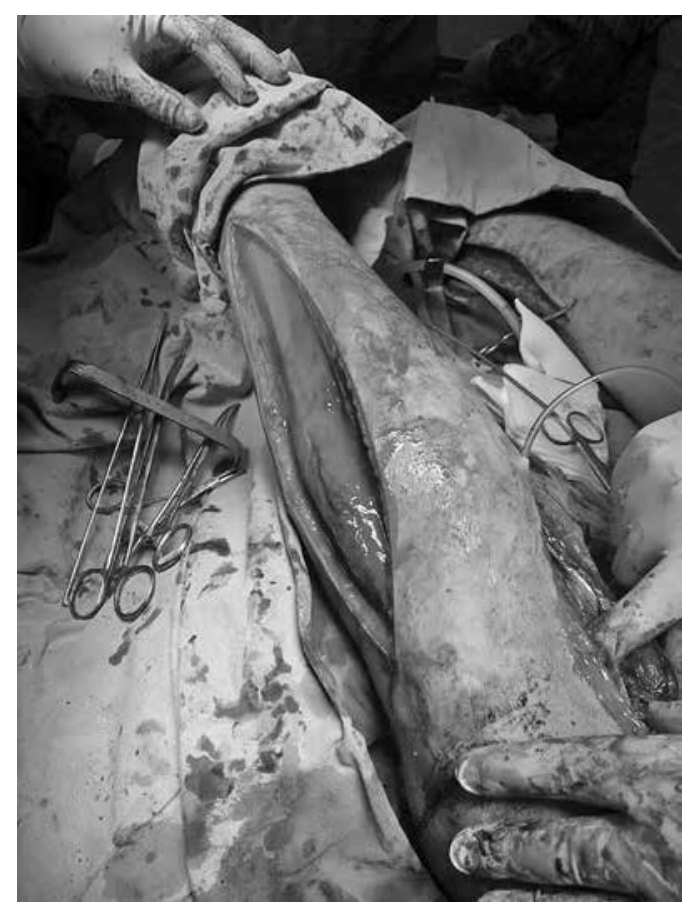

Figure 3. Fasciotomy. approximately $20 \mathrm{~cm}$ saphenous vein was explored from a total amputated counter-limb in one patient and was used for the interposition of the popliteal artery and vein of the other limb with subtotal amputee. In the majority of cases, the fascia and skin were unable to be closed at the end of the operation and the orthopedics department performed fasciotomy to maintain the vascular flow (Figure 3). These types of the highenergy injuries with blast effect of high-density muscle tissue was considered to cause this condition.

In order to achieve the lowest mortality and morbidity in the possible future war injuries, time to hospitalization must be at least $30 \mathrm{~min}$ in vascular injuries. The presence of a well-equipped surgical team who meet the same objectives in harmony to evaluate the injured patient in the emergency room and the availability of equipment and infrastructure to be available to the relevant authorities and to be located in the possible closest location to the war zone can reduce morbidity and mortality, particularly for patients with hemodynamic instability.

In conclusion, although these types of injuries are frequently encountered in war zones, surgeons are faced with such injuries in their daily practice. If these experiences are obtained with the presence of much better organized teams such as in the war zones and can be transferred to routine surgical procedures in their daily practice, we can reduce the damage caused by such injuries in the society and decrease the mortality. We believe that it would be beneficial for our country and the armed forces to specialize in a smaller proportion of surgical teams in primary care centers, particularly which are close to the ongoing internal security operations. We believe that UMKE teams and Turkey's ability to successfully carry out these types of events are effective, since not only Turkey provides surgical team and necessary equipment, but also it launches its field hospitals to the battlefield as closest as possible.

\section{Declaration of conflicting interests}

The authors declared no conflicts of interest with respect to the authorship and/or publication of this article.

\section{Funding}

The authors received no financial support for the research and/or authorship of this article.

\section{REFERENCES}

1. Patel JA, White JM, White PW, Rich NM, Rasmussen TE. A contemporary, 7-year analysis of vascular injury from the war in Afghanistan. J Vasc Surg 2018;68:1872-9. 
2. Kim EN, Kim MJ, You JS, Shin HJ, Park IC, Chung SP, et al. Effects of an emergency transfer coordination center on secondary overtriage in an emergency department. Am J Emerg Med 2019;37:395-400.

3. Fasol R, Irvine S, Zilla P. Vascular injuries caused by anti-personnel mines. J Cardiovasc Surg (Torino) 1989;30:467-72.

4. Zakharia AT. Cardiovascular and thoracic battle injuries in the Lebanon War. Analysis of 3,000 personal cases. J Thorac Cardiovasc Surg 1985;89:723-33.

5. Debakey ME, Simeone FA. Battle Injuries of the Arteries in World War II: An Analysis of 2,471 Cases. Ann Surg 1946;123:534-79.

6. Rich NM, Baugh JH, Hughes CW. Significance of complications associated with vascular repairs performed in Vietnam. Arch Surg 1970;100:646-51.

7. White JM, Stannard A, Burkhardt GE, Eastridge BJ, Blackbourne LH, Rasmussen TE. The epidemiology of vascular injury in the wars in Iraq and Afghanistan. Ann Surg 2011;253:1184-9.

8. Graham JM, Mattox KL, Beall AC Jr. Penetrating trauma of the lung. J Trauma 1979;19:665-9.

9. Moreels R, Pont M, Ean S, Vitharit M, Vuthy C, Roy S, et al. Wartime colon injuries: primary repair or colostomy? J R Soc Med 1994;87:265-7.

10. Edwards DP, Galbraith KA. Colostomy in conflict: military colonic surgery. Ann R Coll Surg Engl 1997;79:243-4.

11. Marshall TJ Jr. Combat casualty care: the Alpha Surgical Company experience during Operation Iraqi Freedom. Mil Med 2005;170:469-72.

12. Uhl C, Grosch C, Hock C, Töpel I, Steinbauer M. Comparison of long-term outcomes of heparin bonded polytetrafluoroethylene and autologous vein below knee femoropopliteal bypasses in patients with critical limb 1schaemia. Eur J Vasc Endovasc Surg 2017;54:203-11.

13. Sakorafas GH, Peros G. Principles of war surgery: current concepts and future perspectives. Am J Emerg Med 2008;26:480-9.

14. Patel TH, Wenner KA, Price SA, Weber MA, Leveridge A, McAtee SJ. A U.S. Army forward surgical team's experience in operation Iraqi Freedom. J Trauma 2004;57:201-7.

15. Ryan JM, Cooper GJ, Haywood IR, Milner SM. Field surgery on a future conventional battlefield: strategy and wound management. Ann R Coll Surg Engl 1991;73:13-20.

16. Bowyer GW. Afghan war wounded: application of the Red Cross wound classification. J Trauma 1995;38:64-7.

17. Conte SM, Vale PR. Peripheral Arterial Disease. Heart Lung Circ 2018;27:427-32.

18. Özkaya Ö, Canlı M, Aysal BK. Yüksek enerjili travmaya maruz kalan hastaların yönetiminde plastik cerrahi yaklaşımının temel prensipleri. Okmeydanı Tıp Derg 2017;33:59-69. 